\title{
Boxeo, espectáculo y deporte. Hacia la construcción de una institucionalidad pugilística en la Buenos Aires de los años veinte
}

\author{
Boxing, show and sport. Towards the construction of a pugilistic institutional framework in the Buenos Aires of the \\ twenties
}

Maria Ullivarri

DOI: https://doi.org/10.24215/2314257Xe113

Centro de Innovación de los Trabajadores (CITRA)-

CONICET-Universidad Metropolitana para la Educación

y el Trabajo (UMET), Argentina

ulliva@gmail.com

Recepción: 03 Julio 2019

Aprobación: 04 Noviembre 2019

\section{ReSUMEN:}

El objetivo de este trabajo es analizar las tensiones en la consolidación del boxeo como un deporte-espectáculo en la ciudad de Buenos Aires durante los años veinte. En ese camino nos interesa empezar a desandar esa malla que fue dando forma y sentido a esa práctica: el crecimiento de los clubes de la ciudad, las oportunidades de trabajo que generó para un conjunto amplio de hombres, la institucionalización, la regulación y la construcción de un universo simbólico en torno al pugilismo que incluía formas e imaginarios sociales, así como también la disputa por el gusto de los espectadores y las formas técnica y boxísticamente adecuadas de llevar adelante un combate. Pensar cómo se construyó una práctica física nos puede permitir adentrarnos en las lógicas más internas de un deporte estigmatizado por un lado y valorado por otro, que fue conformando sentidos y masculinidades en el temprano siglo XX. Palabras Clave: Boxeo, Buenos Aires, Firpo, Deporte, Trabajadores.

\section{Abstract:}

The main purpose of this paper is to analyze the tensions in the consolidation of boxing as a sport-show in the city of Buenos Aires during the twenties. In this way we are interested in starting to retrace that mesh that was giving form and meaning to the practice of that sport: the development of new clubs in the city, the job opportunities that were generated for a wide group of men, the institutionalization, the regulation and the construction of a symbolic universe around pugilism that included social forms and imaginaries, as well as the dispute for the taste of the spectators and the appropriate ways (in terms of technic and style) to carry out a fight.

KEYWORDS: Boxing, Buenos Aires, Firpo, Sport, Working class.

\section{INTRODUCCIÓN}

El 8 de octubre de 1922 un cronista de La Vanguardia quiso ver "por sus propios ojos" un espectáculo de boxeo con el fin de "entender el fenómeno". Los alrededores del Club Sportivo Barracas estaban visiblemente aturdidos, los tranvías con servicio extra llegaban llenos de personas, incluso circulaba un coche especial con la inscripción "Match Firpo-Tracey". Los vecinos se acercaban curiosos para observar el movimiento inusual de la zona y vendedores ambulantes acampaban en los alrededores. Las crónicas relatan que el alcohol y los gritos sobraban. Algunos podían escucharse claramente: “¡A 20 centavos, medallas de Firpo!”

Peleaba el argentino Luis Ángel Firpo contra el australiano Jim Tracey. Las estimaciones hablaban de que el estadio albergaría a 60 mil personas. Las entradas eran accesibles, cinco pesos la más barata, pero algunos palcos llegaron a pagarse 500 pesos (Consejo Deliberante de la Ciudad de Buenos Aires, 1922).

La crónica iba rescatando el espíritu festivo de los momentos previos al evento. Sin embargo, cuando comenzaron las peleas, el relato de este cronista se volvió más sombrío. Las apreciaciones desdeñosas sobre el deporte de los puños no eran nuevas y de estas letanías contra el boxeo el diario socialista La Vanguardia 
había hecho una bandera. Pero no era el único sector que consideraba al boxeo como un espectáculo ajeno a la cultura. De hecho, a los promotores les había costado conseguir el permiso para realizar el evento en Barracas, porque los espectáculos de boxeo estaban prohibidos en la ciudad de Buenos Aires desde 1892 y esa interdicción estaba sostenida sobre un conjunto amplio de explicaciones, la mayoría de las cuales abrevaba en la naturaleza brutal y abyecta del deporte.

La situación, sin embargo, era muy difícil de contener, porque el boxeo se estaba convirtiendo en una práctica muy popular. En muy pocos años había pasado de ser un ejercicio de élites y de marineros extranjeros (Palla, 2018) a ser un deporte practicado por un gran número de aficionados de todas las clases sociales y a formar parte de la oferta de entretenimientos porteños (González Velazco, 2012; Carelli Lynch y Bordón, 2017; Ullivarri, 2019). Internamente el boxeo estaba institucionalizándose a través de la Federación Argentina de Box (FAB), que buscaba establecer reglamentaciones que permitieran una práctica deportiva segura y competitiva, mediante equivalencias, regulaciones y convenios con otras federaciones y naciones. También el pugilismo comenzó a ser objeto destacado en publicaciones periódicas y a tener incluso sus propias revistas especializadas, que trabajaban en la construcción de formas estéticas, morales y culturales de mirar y de practicar el deporte. Es entonces a partir de estos ejes que me paro sobre la idea de que los años veinte fueron un escenario nodal para la conformación de una institucionalización deportiva que intentó ordenar y dar forma a la práctica del boxeo en el país y empezó a perfilar un "sentido común pugilístico".

La historia del deporte no puede pensarse como ajena a la historia social. En el caso particular del boxeo la mirada fue corriéndose de la narración de las grandes peleas hacia la problematización de la práctica dentro de la dinámica social que le daba forma y contenido. Al mismo tiempo esa mirada se detenía sobre los discursos y los imaginarios que componían y atravesaban dicha problemática.

En esa dirección, este trabajo rastrea algunos de los recorridos que fueron componiendo la forma deportiva, regulada e institucionalizada del boxeo en la ciudad de Buenos Aires. Nos interesa pensar también este deporte como una experiencia social de los años veinte porteños, a partir del análisis de las tensiones en la consolidación del boxeo como un deporte-espectáculo, y empezar a desandar esa malla que fue dando forma y sentido a la práctica: el crecimiento de los clubes de la ciudad, la institucionalización, la regulación y la construcción de un entramado de sentidos sobre el boxeo como actividad masculina.

A partir de los años veinte el boxeo atravesó un proceso de difusión social muy amplio, cuya prueba más contundente fue la multiplicación de clubes y de boxeadores por toda la ciudad de Buenos Aires. En 1924 la revista Punch comentaba con asombro: "todos los días se funda un club." (Punch, 23 de diciembre de 1923, p. 12). Fue sin dudas la era de Luis Ángel Firpo la época dorada del desarrollo del boxeo como deporte popular. ${ }^{1}$ $\mathrm{Y}$ es en ese particular escenario donde intentaremos analizar las formas en las que el boxeo era discutido públicamente, era pensado y era practicado en la ciudad de Buenos Aires.

Históricamente el deporte se fue construyendo con la ciudad y formó parte de esa cultura de masas, que transformó las prácticas de consumo de los habitantes de Buenos Aires. En ese sentido, el período de entreguerras estuvo teñido por un clima de interés por la cultura física y la validación de prácticas corporales como la gimnasia, el juego y el esparcimiento al aire libre; por eso resulta un escenario sugerente para pensar los procesos sociales y culturales de la ciudad, los usos del tiempo, los usos del cuerpo, las codificaciones y las transformaciones más cotidianas de las prácticas deportivas, que fueron desde el gimnasio del barrio hasta el Luna Park (Scharagrodsky, 2011, 2014; Roldán, 2009; Reyna, 2011; Servera, 2017; Iwanzuk, 1992; Frydenberg, 2011; Roldán, 2015; Aisenstein y Feiguin, 2012; Andersen y Puppo, 2012; Hora, 2014).

\section{De la Distinción a LO PROFANO}

El boxeo formó parte de esa conexión trasnacional que vinculó a América Latina con Europa a través de sus puertos y luego también de sus empresas de servicios, como los bancos o ferrocarriles (Rinke, 2007; Roldan, 2015). Los diarios británicos mostraban el orgullo de haber traído al país no solo tecnología, industria y razas 
vacunas y ovinas, sino también el gusto y la pasión por los deportes, entre ellos el boxeo (Archetti, 2005). Por eso quizás los primeros registros de peleas en la Argentina datan de las tempranas décadas del siglo XIX y aparecen en el periódico de la comunidad inglesa en Buenos Aires, el British Packet and Argentine News. Allí se publicó la noticia sobre un match entre un estadounidense y un inglés realizado en un local cercano a Retiro (Vila, 2011). Esa nota aseguraba que ese combate sería solo el primero de una serie de encuentros programados (British Packet, and Argentine News, 1929). En las zonas del puerto, los piringundines y bajos fondos siempre podía conseguirse alguna pelea. Luego también se sumaron los teatros, donde el pugilismo formaba parte de espectáculos de varieté con danzas, acrobacias y lucha romana. ${ }^{2}$ Fue justamente luego de uno de esos espectáculos que el Concejo Deliberante de Buenos Aires prohibió el boxeo debido a "la repugnancia que esta clase de espectáculos ofrece" (La Nación, 8 de Septiembre de 1892) y por estar reñido con el buen gusto (La Nación, 6 de Septiembre de 1892).

A pesar de esa prohibición los cultores de deporte circulaban por Buenos Aires (Palla, 2019), pero a principios de los años veinte la discusión se reactivó a raíz de las demandas por su legalización. En esa discusión el comisario retirado Laurentino Mejía publicó en 1921 una carta en la Revista de Policía (1 de Febrero de 1921) en la que relataba el episodio de 1892 en clave de padecimiento:

A la terminación del segundo round, al atleta rubio en su asiento le abanicaban; enjugándose hemorragia sobrevenida por
un guantazo recio; los labios tumefactos han aumentado volumen y perdido forma y las encías derramaban sangre (...) A
esta altura del espectáculo el público no apasionado, lastimado en su moral humana, sentado ya, gritaba: "basta...basta!!" (...)
Un momento después aquel hombre rubio tambaleaba recibiendo golpe tras golpe en la cabeza como no se pega a la bestia,
separaba las piernas buscando equilibrio, y en su fisonomía se veía huir la vida por el único ojo abierto, como sorprendido
de seguir viviendo ante demasiada crueldad; y el público indignado por el horror del espectáculo enarbolaron algunas sillas
mientras otras personas invadían el proscenio (...) Aquello que se había brindado al público no era sport sino un padecimiento
gratuito a sus costumbres en las conquistas que han obtenido de la cultura. ${ }^{3}$

La aparición de esta descripción tan cruda treinta años después se inserta dentro de un conjunto de esfuerzos que algunos sectores de la sociedad porteña llevaron adelante con el fin de impedir que el boxeo rentado fuera permitido en la ciudad. El texto estaba escrito como una carta al concejal Villegas, uno de los impulsores de la derogación de la ordenanza que prohibía el boxeo en la ciudad de Buenos Aires e intentaba demostrar que el boxeo no solo causaba sufrimiento a sus practicantes, sino que también lo hacía a quienes lo observaban.

La descripción contemporánea del espectáculo, así como el retrato de Mejías, permite ver cómo se ponía en tensión la disputa por el gusto y el espectáculo en la ciudad de Buenos Aires, donde el boxeo era pensado como una variante de la riña. Pero esa repugnancia estaba también atravesada por la necesidad de impedir o controlar las diversiones populares que facilitaran la reyerta, o cualquier otra acción de conflicto social en una ciudad que estaba creciendo aceleradamente. Ana Cecchi (2012) señala que durante el período 1890-1902 la ciudad de Buenos Aires redefinió las pautas de legalidad admitidas en el ámbito urbano, estableciendo un orden de prácticas permitidas y aquellas que entraron en el campo de los prohibido, como las riñas de gallo, las corridas de Toro y el juego fuera del monopolio estatal. Esta suerte de frontera entre lo legal y lo ilegal le asignó a la policía nuevas funciones, según las cuales toda forma de violencia, incluso aquella regulada o reglamentada, debía desaparecer de los espacios públicos.

A pesar de estas interdicciones, en los albores del siglo XX la práctica del boxeo ya estaba instalada en la ciudad. El arte de los puños se extendía por bajofondos portuarios, teatros y hasta misiones de marineros extranjeros (Palla, 2019). Pero también era parte de las paradigmáticas expresiones del ocio de la élite porteña, en la que el vínculo con los deportes, especialmente ingleses, constituía un repertorio fundamental de su distinción como grupo social (Losada, 2009) ${ }^{4}$. Estos sportmen adoptaron las reglas internacionales del boxeo y destacaron la importancia de la cultura física. "Los baños de sol, la higiene fisiológica, el estímulo de la virilidad", que según palabras de César Viale, primer presidente de la FAB, "no habían sido todavía comprendidos en la gran aldea" (La Nación, 9 de Abril de 1920). 
En ese universo de sentido, que abrevaba en cierta incomprensión de la práctica, se fueron abriendo algunas academias de boxeo y de savate, la versión francesa del boxeo. Pero todavía en los primeros años del entresiglo, "los torcidos", como se denominaba al círculo que practicaba el pugilismo, eran un grupo muy reducido (El Gráfico, 25 de Enero de 1952). Tanto era así que frente a una pelea en el club del Progreso en 1901, la revista Caras y Caretas (26 de Octubre de 1901: 32) comentaba, con algo de extrañamiento, que el espectáculo parecía una riña de gallos entre aficionados a la fuerza física.La Vanguardia (20 de Septiembre de 1910) solía también equiparar la riña de gallos con el box y denunciaba con frecuencia que entusiastas de este deporte se daban trompis en los parques de la ciudad, lo que constituía "una escena repugnante y hasta un peligro para los paseantes".

Los esfuerzos por presentar al boxeo como algo distante de la riña atravesaron los primeros años del siglo. Cesar Viale, desde La Nación o Caras y Caretas, se esforzaba por describir lo que él consideraba la estética depurada del boxeo, una "esgrima de los puños (...) principal encanto para quienes seguían de cerca las alternativas del que es en sumo grado artístico juego cuando se lo toma con conciencia y altura” (Viale, 1922, p. 51).

Muy lejos de poder encontrar belleza allí, la prensa detractora del boxeo miraba la práctica con "una sensación de vergüenza, más que de horror", como decía La Vanguardia. Frente a ellos, este circuito de aficionados divulgaba revistas extranjeras y trabajaba en la fundación de clubes, a muchos de los cuales solían llegar boxeadores extranjeros que se instalaban en Buenos Aires y oficiaban de profesores. Pero también marineros británicos o miembros de compañías de teatro, que bajaban de los barcos buscando compañeros de guantes. Constancio Vigil recordaba en sus crónicas que eran grandes "las palizas que se daban con esos que bajaban de los barcos".

El boxeo era una práctica global que participaba de un universo de valores compartido por los hombres que lo practicaban, donde el ring era considerado un escenario de honor" y donde los boxeadores "al poner en juego sus músculos (...) tendrán oportunidad de hacerse admirar por los extraños siendo bravos y gentiles y de envanecer a sus padres, maestros, persiguiendo los consagratorios títulos de campeones adentro y fuera del ring" (Viale, 1922, p. 51).

Esta suerte de práctica ritual de la masculinidad los conectaba con una tradición de guerreros. Pero esta circulación de peleadores no solo se alimentaba del honor, sino que también sostenía un circuito de combates por apuestas que se realizaban en "teatros de última categoría" (Viale, 1922). En esa dirección, el vínculo entre dinero y boxeo fue constitutivo de la actividad. En octubre 1903 esa conformación se institucionalizó y dio forma a la primera pelea profesional en el país, cuando el irlandés Paddy Mac Carthy se enfrentó con el italiano Abelardo Robassio en el local de la revista El Gladiador. ${ }^{6}$

A partir de allí, en el universo del boxeo comenzaron a realizarse combates que convocaron al público porteño y visibilizaron la popularidad de una actividad clandestina. ${ }^{7}$ Caras y Caretas comentaba en su edición del 19 diciembre de 1908 (p, 68) que había sido "una sorpresa la creciente popularidad del box en Buenos Aires", refiriéndose a un encuentro entre boxeadores argentinos y marineros. Parte de esa popularidad apareció materializada en la fundación de clubes y en la llegada de nuevos profesores que hicieron crecer la escena. En 1909 se realizó el primer campeonato nacional de aficionados y a partir de allí las competencias se sucedieron casi sin interrupciones. Así, desde fines de los años diez principios de los años veinte el circuito de campeonatos se extendió y se pueden registrar desde intercolegiales hasta campeonatos universitarios, policiales, de las fuerzas armadas, médicos, etc.

\section{LA INSTITUCIONALIZACIÓN Y LA REGULACIÓN}

El boxeo era un deporte relativamente nuevo, que siempre había tenido un estatus legal inseguro y variable. La geografía del deporte, por lo menos en los primeros años, se fue modificando al compás de la situación de legalidad que presentaba (Taylor, 2013, p. 236). Boxeadores y promotores se movían por las ciudades y países 
buscando oportunidades de combate y legislaciones más permisivas. Estos movimientos también abarcaban los trayectos transoceánicos que acercaban boxeadores al país (Palla, 2018).

Las reglamentaciones fueron variando en los estados a lo largo del tiempo, pero siempre tuvieron como característica la mirada con sospecha (Rodríguez, 2009) porque, en mayor o menor medida, el boxeo siempre suscitó resquemores en las autoridades. En la Argentina, desde fines del siglo XIX, los teatros y cafés se convirtieron en escenarios privilegiados, así como también toda la zona portuaria de "bajofondos y piringundines", el Parque Lezama y las misiones de marineros. Antes de su institucionalización, tanto a nivel nacional como internacional, el deporte de los puños se manejó como un conjunto de redes o a través de formas de sindicalización, agremiación o federación de clubes, promotores o boxeadores, y luego también en comisiones reguladoras en las ciudades. En la Argentina, los primeros intentos de fundar una institución que regulara la práctica datan de 1908, pero fue recién en 1920 cuando vio la luz un proyecto de organización (Demárcico, 2007; Viale, 1922). La FAB fue fundada el 23 de marzo de 1920 por representantes de los clubes de boxeo más importantes de la ciudad de Buenos Aires. ${ }^{8}$ Había cierta ansiedad por negociar la derogación de la ordenanza que prohibía los combates, porque esto garantizaría, a juicio de estos hombres, un crecimiento exponencial de la actividad. A decir de muchos miembros de las primeras comisiones directivas de la FAB, esa posibilidad convertiría a Buenos Aires en el centro del pugilismo sudamericano.

Pero las autoridades porteñas destacaban el peligro de su popularización y la posibilidad de que esa violencia contenida resultara material de emulación fuera del ring. La prohibición del boxeo era leída como un mecanismo regulador de las pasiones, pero frente a estos análisis, las argumentaciones de la FAB, los clubes, la prensa y los defensores del boxeo, sobre todo frente a las corrientes prohibicionistas, solían asentarse en la idea, quizás poco probada, de que el uso controlado de la violencia a través del pugilismo permitiría soliviantar la criminalidad "de revolver y puñal" en la ciudad. El Gráfico (13 de Enero de 1923) publicaba notas sobre niños practicando boxeo y señalaba que servía para "desarrollar el instinto combativo del hombre y para enseñarle la defensa propia, sin armas (...) constituyendo un bien para el hombre y para el Estado". Estas especulaciones no eran exclusivas de la Argentina, ya que se repitieron en varios países, como México (Bolio, 1923; Cortes Ancona, 2015), Inglaterra y Estados Unidos, donde el boxeo era visto como una influencia "civilizatoria" que servía para canalizar la "violencia masculina", al mismo tiempo que promovía virtudes en esos hombres, tales como el coraje, la fuerza y la resistencia (Scott, 2015). Había un profundo cariz moral atrás de estas ideas. César Viale (1922, p. 108) subrayaba en una carta enviada al Concejo Deliberante de la ciudad que "dentro del ring el carácter se educa, el cuerpo se fortifica, el hombre se disciplina y el caballero se destaca”.

Frente a estas narrativas, los detractores utilizaban el carácter sedicioso asignado a las peleas como una preocupación frente a la posibilidad de tumultos, asambleas ilegales o alborotos (Anderson, 2001). Fue en el Concejo Deliberante de la ciudad donde todas estas discusiones cobraron forma. La posición mayoritaria respecto al boxeo, pero especialmente al boxeo rentado, sostenía que esta actividad era lindante con "actos de incultura" y prostitución; incluso algunos de sus defensores esgrimían que la profesionalización era una "degeneración" del propio deporte. Los concejales socialistas, aun frente a la masividad de los matchs, denunciaban "los intentos de injertar el boxeo" en el país. Otros concejales explicaban que "a la par de la cultura física se fomenta la incultura de los sentimientos" ( Concejo Deliberante de la Ciudad de Buenos Aires, 1922:2162 y sig.). Algunos incluso decían acordar con el ejercicio, pero argumentaban que no debía permitirse "el espectáculo del KO". ${ }^{9}$ Estos argumentos eran apoyados por La Vanguardia (7 de Octubre de 1922) y La Prensa (2 y 3 de Octubre de 1922), que utilizaban la publicación de noticias sobre la prohibición del boxeo en otros países. Y llegaron incluso a pedir a la policía que directamente pusiera fin a los matchs de boxeo. Uno de los argumentos más ilustrativos marcaba la diferencia entre el deporte que se practicaba y el que se presenciaba, y definía el gusto por ver peleas como un acto "masturbatorio" (Consejo Deliberante de la Ciudad de Buenos Aires, 1923: 2731).

La forma en la que el boxeo era discutido públicamente revelaba las ansiedades de una sociedad que se transformaba y con ella las prácticas corporales de los nuevos sectores que se incorporaban a la vida deportiva 
de la ciudad. Así, a pesar de que se pensaba que la existencia ordenadora de la gimnasia y de la actividad física "restringía el espacio al imperio de los desvíos" (Barrancos, 2014, p. 14), había usos del cuerpo que no debían permitirse. Frente a esto, los trabajadores tenían en el disfrute del tiempo libre la posibilidad de discutir los consumos, los gustos y las fronteras morales. Por eso el cuerpo y las pasiones entraron en la discusión central del boxeo. No solo se hablaba de los pugilistas, sino también de los nuevos fervores que se generaban en las audiencias. En ese sentido, los concejales socialistas señalaban, por ejemplo, que "los profesionales del box son todos hombres sin cultura. Sin embargo, el pueblo los convierte en sus ídolos" (Consejo Deliberante de la Ciudad de Buenos Aires, 1923: 2736). El hombre nuevo estaba muy lejos de admirar esa forma de entretenimiento tan brutal (Martínez Mazzola, 2013). En esa línea también decía Romero Brest (1929, p.8), pionero de la educación física en el país, que "la brutalidad es admirada por el hombre primitivo y por el niño, que la reconocen como la fuerza incontrastable que son capaces de apreciar".

Frente a esa embestida, la fundación de la FAB funcionó como espacio de lobby para lograr la derogación del artículo 1081 del digesto municipal que prohibía los matchs de boxeo. Tras los primeros fracasos, en 1921 se presentó otra iniciativa para abolir la ordenanza. El concejal socialista Villegas, en contra de la posición sostenida por su partido, señaló que iba a apoyar la iniciativa de la FAB, trabajando fundamentalmente sobre los "vulgares prejuicios" de los detractores del pugilismo a fin de lograr el asentimiento de las autoridades (El Gráfico, 15 de enero de 1921).

El esfuerzo tuvo resultados, pero la ordenanza que permitía el box fue vetada por el intendente José Luis Cantilo. Los fundamentos del veto abrevaban en una cuestión que adquirió centralidad en la historia del boxeo, la del monopolio sobre la fiscalización. El intendente alegaba que la ciudad estaba entregando a una institución privada, la FAB, la función esencialmente gubernativa de controlar.

Luego de los Juegos Olímpicos Latinoamericanos en Río Janeiro de 1922, en los que el boxeo cosechó tres medallas, los defensores del boxeo volvieron a presionar. ${ }^{10}$ Boxeadores, concejales y también $\mathrm{FAB}$ presentaron notas (Crítica, 13 de Octubre de 1922). Incluso Firpo fue a hablar con los concejales y facilitó las herramientas constitutivas de la Comisión Atlética de Nueva York, que regía el boxeo en esa ciudad (Estol, 1946).

Luego de un trabajo arduo y de ciertos consensos, a fines de 1923 se consiguió el número de votos necesario para derogar la ordenanza. Y, para evitar el monopolio, se constituyó una Comisión de Box, bajo la égida de la Municipalidad de la Ciudad de Buenos Aires, con dos personas designadas por el Concejo y dos por la FAB, votados por los clubes. La presidencia quedaría en manos del director de Plazas de Ejercicios Físicos.

Por otro lado, la necesidad de separar el boxeo de un simple linchamiento ocupó una parte importante de las discusiones en el Concejo Deliberante. Un requerimiento solicitado fue el tamaño de los guantes. Hasta ese entonces se peleaba con guantes de cuatro onzas, lo que, acompañado de cierta indiferencia respecto a las equivalencias, provocaba daños en los boxeadores y fundamentalmente permitía que la mayoría de las peleas terminaran en KO. Este tipo de situaciones hacía más brutales los combates y convertía al boxeo en un espectáculo de la derrota. No era descabellado pensar que las fotos de portada que publicaba la prensa con hombres dormidos sobre un ring podrían profundizar el rechazo que existía en parte de la sociedad. Por eso algunos concejales pidieron que se elevara el peso de los guantes a seis onzas para pesos "microbio", y a doce onzas o más para pesos pesados. También las equivalencias de peso eran un problema frecuente. En algunas peleas donde la diferencia de peso era notable -más de 10 kilos- se estilaba dar al boxeador más pesado un guante más grande. ${ }^{11}$ Sin embargo, El Gráfico (8 de Julio de 1922) decía que permitir algunas peleas era "una obra criminal".

La prohibición del boxeo no era un tema menor en la ciudad de Buenos Aires. Mediante un permiso especial se concretó el match Firpo-Tracey en Barracas y quedó demostrada la enorme popularidad del deporte. En ese sentido, la disputa por los permisos dejaba claro que de ninguna manera era lo mismo realizar los encuentros en Avellaneda, Lomas de Zamora, el Mercado Central. La ciudad crecía aceleradamente y los habitantes habían dado claras muestras de su gusto por el pugilismo, pero también los promotores habían encontrado en la actividad una posible fuente de ganancias y el registro de boxeadores crecía aceleradamente. 
Todas las peleas, desde las estelares de fondo hasta las preliminares, implicaban una estructura sostenida por una fuerza de trabajo. Entre 1925 (cuando comenzó a registrarse) y 1939, la FAB entregó 9053 licencias de aficionado (Cuaderno de Licencias Amateurs 1925-1939). Prueba de la popularidad del deporte también resultan las inscripciones al campeonato de novicios en 1924, donde se presentaron 800 púgiles, desbordando las expectativas (Punch, 11 de enero de 1924:12). El registro de profesionales también era prolífico, en los cuatro primeros años de funcionamiento la $\mathrm{CMB}$ otorgó casi 250 licencias para la ciudad. Ese ordenamiento también acompañó la aparición del boxeo como un espacio destacado de logros deportivos internacionales, que llegó incluso a conseguir cuatro medallas en los Juegos Olímpicos de París de 1924.

Estas discusiones acompañaban los conflictos institucionales de una organización con una estructura en formación. La FAB tuvo su primera división en 1922, cuando un grupo disidente de clubes formó la Asociación Argentina de Boxeo (AAB). La prensa acusaba a la FAB de haberse desempeñado con errores en los albores del pugilismo, pero era verdad que no tenía la experiencia para evitarlos, porque recién comenzaba a trabajar en un mundo que no parecía fácil de regular (El Gráfico, 4 de Noviembre de 1922). Por otro lado, la pelea entre las organizaciones estaba en el centro de una discusión mayor, el monopolio sobre una actividad que prometía ser muy rentable. ${ }^{12}$ A fines de 1923, casi como condición para lograr la derogación del digesto que prohibía el boxeo en la ciudad, y porque urgían los tiempos de las competencias internacionales, las organizaciones se volvieron a unificar.

Para la FAB construir ese monopolio fue parte de su estrategia política más activa y más necesaria. Para ello contó con el apoyo de las autoridades de la ciudad de Buenos Aires. En esa dirección la reglamentación de la ordenanza que permitía el boxeo decía explícitamente que era "requisito indispensable que la federación fiscalice los matchs" (Punch, 29 de Marzo de 1924:3). Por su parte, la FAB publicaba recurrentemente avisos en la prensa, informando sobre la suspensión de boxeadores que participaran de campeonatos o matchs no fiscalizados, a quienes consideraban "personas extrañas" al boxeo.

¿Pero qué era la FAB? La prensa producía imágenes y descripciones que configuraban simbólicamente los deberes de las autoridades del boxeo y sus áreas de intervención, pero desconocían el trabajo que implicaba conformar un universo de legitimidad sobre organizaciones y sentidos que venían funcionado de manera autónoma desde tiempos pretéritos. Los clubes entendían que la FAB, que había sido su creación, había adquirido vida propia y conspiraba contra ellos. En el mundo del boxeo, la Federación apareció como un hecho ajeno, distinto a la naturaleza de la escena. "Nosotros somos el boxeo", declaraban algunos clubes a la revista Punch. La organización de clubes en una federación exigía llevar adelante una suerte de cesión de derechos, hecho que no todas las instituciones entendieron de la misma forma. Algo de esto pudo verse en 1924, cuando la FAB volvió a dividirse y diversos clubes designaron sus comisiones directivas. ${ }^{13}$

Para la federación no fue sencillo fiscalizar el boxeo, porque esta práctica era mucho más que la estructura de combates permitidos. Muchos festivales escapaban a su control, y provocaban el enojo de la prensa, sobre todo cuando se presentaban espectáculos de menores o peleas de estilo callejero. Pero la aparición de la FAB sí permitió sostener una cierta escala de equivalencias de peso y experiencia, y promocionó campeonatos, títulos y rankings. La posibilidad de controlar los permisos a través de las licencias logró que pudieran establecerse ciertas reglas para establecer un orden de jerarquías internas en el boxeo. Al mismo tiempo, la FAB garantizaba los controles médicos regulares de los boxeadores y los deberes de las autoridades del ring, que apuntaban al cuidado de los contendientes y a protegerlos de los efectos más graves de los golpes.

Esta organización, en conjunto con las vinculaciones internacionales, permitió ampliar los horizontes nacionales de un deporte que ya tenía un sesgo trasnacional muy marcado. La Federación adhirió a las reglas de la International Boxing Union, con sede en Paris. Esto le permitió dar forma a los detalles de los matchs en materia de medidas oficiales del ring, vestimenta, pesos, duración y número de rounds, autoridades, vendas, guantes, segundos y reglas del combate. La Federación dio forma institucional también a los títulos nacionales y a la organización de títulos sudamericanos. Este proceso de construcción de consensos internacionales y 
nacionales consolidó la estructura del boxeo, articulada en torno a récords y equivalencias (Loudcher, 2013, p. 2017).

En paralelo, la ciudad de Buenos Aires fiscalizaba el boxeo profesional a través de la Comisión Municipal de Boxeo, cuyas autoridades principales gustaban de presentarse a sí mismas como una barrera al modo caprichoso con el cual se había venido manejando el mundo del boxeo. La comisión se encargaba de controlar la salud de los boxeadores, someterlos a pruebas de suficiencia en caso de ser necesario y también controlar sus antecedentes policiales para "depurar el medio pugilístico de elementos no deseables" (El Gráfico, 6 de Diciembre de 1924). Por otro lado, la Comisión también pesaba a los boxeadores antes de las peleas, y pesaba asimismo los guantes, que eran enviados en bolsas precintadas al lugar del combate. Controlaba los contratos y garantizaba la igualdad de condiciones en cada match. También tenía la atribución de entregar las licencias a boxeadores, mánager, segundos, jueces, promotores, etc. ${ }^{14}$ Con esa facultad fiscalizadora y punitiva se convertía en una instancia política fundamental, en tanto, en términos de boxeo profesional, sus facultades estaban por encima de las de la FAB en el ámbito de la ciudad

La participación del estado en espectáculos deportivos era una forma de poner sobre el tapete la necesidad de garantizar las regulaciones, pero también de garantizar ingresos municipales. Muchos de esos impuestos eran costosos para las organizaciones deportivas y también para los deportistas, ya que en algunos casos llegaron a ser del $30 \%$ de la bolsa o las ganancias. Este asunto fue muy discutido porque el financiamiento del boxeo dependía fundamentalmente de los espectadores. Por eso, cuando todavía regía la prohibición de los eventos, se realizaban pequeños espectáculos, muchos de los cuales no alcanzaban para cubrir grandes bolsas y le quitaban liquidez a la actividad.

Entre los años 1921 y 1923 se registraron 73 festivales grandes en clubes de la ciudad, que aparecieron en la prensa. Es indudable que frente a la clandestinidad, existían otros espacios sin difusión. A partir de la derogación de la ordenanza, en los tres primeros meses de reglamentación se registraron 170 festivales en clubes y teatros (enero a marzo de 1924), con un promedio sostenido de 60 festivales por mes. Entre ellos comenzaba a destacarse el Luna Park, que ofrecía varias veladas semanales y que competía con los tradicionales y más pequeños festivales en los clubes. De esta forma, tanto para los espectadores que gustaban de esos espectáculos con cartelera llena como para los boxeadores, esto comenzó a resultar más atractivo y redituable que los rings de los clubes. Asimismo, de los 15 clubes que fundaron la FAB en 1920, se llegó a 169 clubes en 1950.

La popularización del boxeo y de otros deportes como el fútbol o el turf estuvo vinculada al desarrollo de una industria del espectáculo. El deporte era un espacio de dispersión o "desrutinización” en un universo de control (Elias y Dunning, 2016, p. 294), que acompañó el mejoramiento de las condiciones de vida y la conquista de derechos por parte de los y las trabajadoras (jornada, salarios), que abrieron nuevos horizontes de consumo: cine, circo, ferias, deportes, teatro, cafés, cabarets, carreras, paseos (Gonzalez Velazco, 2012; Otero Carvajal, 2003; Guiamet, 2016; Armus, 1996). Matthew Taylor (2009) señala que el boxeo articulaba perfectamente esa forma de "entretenimiento nacional" con la identidad más local y barrial de la ciudad, todo lo cual conjugaba perfectamente con el crecimiento del tiempo de ocio de los porteños. Parecía no haber contradicciones en la resolución de ese sentido que fue adquiriendo el boxeo en los años veinte. ${ }^{15}$

\section{EL BOXEO COMO NOTICIA Y COMO ESPECTÁCULO}

Otro de los actores centrales en el desarrollo del boxeo fue la prensa. Desde las publicaciones especializadas se realizaba una enérgica intervención cultural acerca del valor del cuerpo y la actividad física en la modernidad (Bergel y Palomino, 2000). Paralelamente, estas narrativas construían un relato deportivo que configuraba simbólicamente lo socialmente aceptado desde la práctica y la reglamentación, y que incluso discutía una pedagogía del espectador. De alguna manera quedaba claro que el crecimiento de la ciudad y la transformación de algunos deportes en espectáculos permitieron convertir el valor y el significado del cuerpo y de la actividad 
física, pero también comenzaron a perfilar una identidad nacional asociada a algunos equipos o deportistas, y también a trabajar en la institucionalización de las organizaciones deportivas.

Brenda Elsey (2011) trabajó fuertemente la idea de que a través del deporte países como Chile pudieron fomentar la participación ciudadana, la formación y la creación de espacios de encuentro de clases medias, trabajadoras y élites, bajo la dirección del proyecto político de estos últimos. En el país algo de ese proceso aparece en la pluma de Viale, aunque también la idea del cuerpo como un bien perfectible, que no solo es social sino también político, aparece en la revista El Gráfico (Archetti, 1995; Bergel y Palomino, 2000; Bontempo, 2012).

Las intervenciones de la prensa no eran en ese sentido menores, porque estaban dando forma a un debate público que en los años veinte se amplió con la presencia del radicalismo en el poder.

La idea de dos hombres golpeándose en un ring parecía no encajar en algunos proyectos políticos. Por eso cuando el cronista de La Vanguardia en el evento de Firpo-Tracey no pudo mirar más que la ferocidad del espectáculo, en realidad no podía dejar de ocultar su incomprensión respecto a lo que estaba observando. El relato se acercaba al desenlace. Cuando se anunció la pelea de fondo, Firpo versus Tracey, la multitud estaba ansiosa. Luego del triunfo del boxeador argentino, que fue tapa de diarios y revistas, y que constituyó uno de los espectáculos de boxeo más grandes realizado en Sudamérica, el periodista del diario socialista concluyó que "aunque la presencia de un clérigo formidable lo santificara, el espectáculo nos pareció sencillamente bárbaro y pernicioso para la educación popular”.

La civilización y la barbarie como clivajes históricos se redefinían en clave deportiva. Por eso exigió prohibirlo para evitar cualquier posibilidad de que se despertara el interés en el deporte "fomentando, en cambio, los realmente sanos" (La Vanguardia, 9 de Octubre de 1922). La prensa contraria, dice Bonuome (2016, p. 121), exhibía las ansiedades y contradicciones que le generaba constatar que aquello que se suponía era una herramienta de emancipación de los trabajadores, el consumo popular, en realidad se había convertido en una máquina de hacer dinero a costa del "embrutecimiento popular".

El boxeo siempre estuvo envuelto en un aire dramático, no solo porque las imágenes de boxeadores caídos llamaban la atención, o porque la vida de muchos de ellos estaba atravesada por el desgaste físico y los daños corporales, sino también por los intereses económicos, los vínculos políticos involucrados en la escena y también por los comportamientos del público (Cortés Ancona, 2015). La multitud enfervorizada o muchas veces enojada, las páginas escritas y el clamor popular por los ídolos convertían al boxeo en un fenómeno de masas de tintes muy populares. Cuando Firpo venció a Tracey por KO en el cuarto round, las crónicas hablaron de un héroe nacional. Virilidad, coraje, verdad, eran dimensiones fundamentales de la masculinidad y se asociaban a los nuevos ideales corporales de la modernidad, como belleza y condición física (Mosse, 1985; Archetti, 2001, p. 15), que permitían pensar un hombre argentino.

De alguna manera Firpo representaba la gloria masculina que se expresaba en esa liturgia de violencia codificada y controlada, y que se consagraba a partir de la aniquilación de la conciencia del adversario o de su incapacidad física para seguir peleando (Rauch, 1993). Los festejos por el KO develaban que el boxeo, como actividad de masas, no dejaba de ser una contracultura intensa, que, aunque condenada por el buen gusto, hacía de eso que el cronista de La Vanguardia entendía como violencia, una celebración. Pero la emoción del combate en tierra patria se complementó con ese hito del boxeo que fue la pelea Firpo-Dempsey, a partir de la cual el boxeador, en una nueva resignificación histórica, fue colocado a la par de figuras como San Martín (Arnoux Narvaja, 2018). Desde el diario Crítica, por ejemplo, pedían que se declarara "héroe nacional de primera magnitud al benemérito ciudadano don Luis. A. Firpo". El diario reflejaba el sentir de las multitudes. Incluso Romero Brest (1929, p. 6), detractor del boxeo, relataba que una amiga le comentó que "desde que he visto al pueblo de mi país moverse entusiasmado en manifestaciones grandiosas, he sentido yo también el sentimiento de la patria y el afecto por el box: ahora soy firpista!"

La esencia poética de estas ideas perfilaba la imagen de un luchador de la patria, y tenía su apologista principal en la pluma de Viale (1922, p. 81), quien escribía que "los campeones como porción y carne que 
son del organismo del pueblo, -el que es idealmente invisible- lo mismo surgen de arriba, del medio, que de abajo". En una línea quizás similar, Wacquant (2007, p. 35) afirmaba que los boxeadores

son héroes populares, no figuras trascendentales. Son de la gente, no están por encima de la gente. No tienen poder; más bien lo que poseen es estilo. No importa tanto lo que hacen, sino la manera en que lo hacen y el hecho de que lo hagan de una manera que afirma, establece, atestigua su singularidad y su capacidad de crearse a sí mismos.

En ese sentido, Roldán (2009) explica que estos relatos, de los cuales el de Firpo era el más poderoso, muestran que un "peleador" sin virtuosismos plásticos ni destreza técnica, o por lo menos no completamente depurada, pero con voluntad y ganas de subir al ring a derrotar al adversario a fuerza de golpes, puede alcanzar grandes éxitos (Estol, 1946, p. 58). Estas narrativas se presentan como ejemplos de un valor esencial e inalterable, reproducido en las revistas deportivas, que son las condiciones de posibilidad del éxito de personajes que tenían un sinfín de adversidades para alcanzar sus sueños (Roldán, 2009), los cuales reproducen también la esencia de una sociedad sostenida en un afán de ascenso social (Karush, 2013). Esta posibilidad generaba una suerte de democratización de las oportunidades, porque ese camino se sostenía sobre un "capital corporal”, cuya distribución, como señala Wacquant (2007), era relativamente independiente de otras formas de capital o poder que circulaban en la sociedad y de las cuales muchos sectores sociales han sido históricamente excluidos.

Y esto tenía algo de sentido porque en el cambio de década el boxeo se convirtió en un trabajo de clase obrera, un medio para ganarse la vida o para mejorar los ingresos entregando un bien tangible, el cuerpo y sus habilidades. Fue durante los años veinte cuando el boxeo comenzó a anclar en los entresijos proletarios de la ciudad. Los canillitas animaban las veladas boxeando "al gallito ciego" y peleaban mientras el público les tiraba monedas que luego ellos recogían. ${ }^{16} \mathrm{El}$ mediano Luis Galtieri relataba que tuvo diversos oficios, siempre con míseros jornales en fábricas y talleres; luego fue sastre, pero consideraba esa labor como propia de mujeres y sentía, además, horror por el taller, que "era pieza sombría y triste". Luego consiguió trabajo de encuadernador, donde cosía y encolaba libros, pero él "aspiraba a un oficio recio" -decía- y entonces consiguió trabajo de herrero (El Gráfico, 26 de Julio de 1924). Fernando Villalba fue lustrabotas, Abelardo Hevia trabajó como mucamo en la casa de una familia que lo adoptó, Gutavo Leneve fue mecánico, Joe Walls fue obrero fideero, Vicente Olivieri era albañil, Claudio Sáez fue dependiente de una librería, Abel Adán fue peluquero, Augusto Viotti fue mecánico y Emilio Battilana fue panadero (El Gráfico 6 de Septiembre de 1924; Punch, 18 de Abril de 1924).

Frente a los 60 pesos que declaraba Galtieri en su primer trabajo, las bolsas eran un horizonte de aspiraciones (El Gráfico, 27 de Mayo de 1922). Sin embargo, para el conjunto más amplio de boxeadores, sobre todo para los pesos más bajos, esta profesión era de sacrificio y poca recompensa, porque sus bolsas, en la mayoría de los casos, no superaban los 100 pesos. ${ }^{17}$ Por eso la profesionalización no era la única condición para poder vivir del deporte. Los trabajadores no podían dedicarse por completo al boxeo ni hacerlo solo por amor. Su tiempo de entrenamiento y competencia estaba determinado por el tiempo de trabajo; incluso algunos boxeadores jóvenes - como era el caso del campeón sudamericano González Pardo- debían cuidar de sus padres enfermos (Punch, 3 de Noviembre de 1923:13).

Aunque difícil para muchos, el profesionalismo dio al boxeo un nuevo sentido. Pasó de ser un símbolo de distinción social en términos de clase, a pensarse como un trabajo deseado por los trabajadores, en términos de prestigio y ascenso social. Pero justamente este deseo de crecer económicamente se ubicaba como otro de los ejes de prejuicios que circulaban en torno al deporte. Ernesto Baum, un amante del boxeo que viajaba por el mundo asistiendo a veladas, comentaba al cronista de Punch: "Me gusta el boxeo como deporte simplemente. Como medio de vivir me parece repugnante" (Punch, 16 de Noviembre de 1923:6).

La narrativa del amor al deporte fue uno de los flancos de ataque al boxeo, pero se fue desarmando al compás de la expansión de la oferta y la demanda de espectáculos deportivos. Y fue la misma prensa la que pasó de defender las prácticas no rentadas a demandar la necesidad de profesionalización. Este proceso fue mucho 
más claro en el caso del fútbol, pero puede verse también en las letanías sobre el boxeo (Servera, 2017; Reyna, 2015). Algo de esto tenía que ver con que el boxeo fue comunicado y perfilado a través de prensa detractora como La Vanguardia o La Prensa. Sin embargo, también tenía prensa afín, como Crítica, que fue uno de los diarios que con más pasión cubrió el mundo del boxeo. A partir de octubre de 1922 agregó a sus páginas una sección fija que se llamaba Noticiario del Box, la cual fue creciendo hasta llegar a ocupar una o dos páginas e incluso ser portada del diario. La circulación de las noticias habilitó un escenario de personas informadas y curiosas sobre los resultados. El mercado editorial abocado al boxeo también incluía las revistas deportivas como el Sport Ilustrado o El Gráfico, que cubrían con mucha atención los pormenores del deporte; también vieron la luz revistas especializadas como Punch o Boxeo Argentino.

El boxeo, como deporte global, fue entrando en las noticias a través de la sección telegramas y cables de los diarios, donde se comentaban los resultados de las peleas internacionales.

La radio fue también apareciendo como un espacio de difusión. Fue la pelea Firpo-Dempsey la que habilitó una nueva forma de transmitir. Ese 14 de septiembre de 1923 en Buenos Aires se esperaban con ansiedad las noticias de Nueva York. Miles de personas se congregaron frente a los diarios La Nación, La Razón y Crítica. La radio transmitió de manera muy especial el combate: se leían los cables telegráficos que llegaban. Para aquellos que no tenían radio, las noticias se transmitían también en Crítica y en el Luna Park. Y aunque la pelea duró apenas un round y medio, la transmisión fue mucho más larga, hasta que finalmente el locutor señaló "Luis Ángel Firpo, el futuro campeón mundial de todos los pesos... perdió por knock out en el segundo round" (Ulanovsky, 2009). La multitud se entristeció, pero ese fenómeno desató un incremento en la venta de radios (Ulanovsky, 2009).

La transformación del deporte como práctica de una élite al deporte como espectáculo masivo se acompañó con el crecimiento de instituciones y organizaciones que se apropiaron y dieron significados a esas prácticas. La prensa, a través de las formas de informar fue una de ellas. Así, no solo construyeron sentidos, sino que también sirvieron para delimitar un campo cultural, mostrar las formas adecuadas de leer una práctica, delinear de esta forma el gusto masivo y también orientar el tiempo libre de los trabajadores.

El Gráfico señalaba muchas veces la dignidad de los boxeadores "que no se venden". En ese sentido, durante los primeros años de regulación del boxeo, la idea del "tongo", la pelea a desgano, "peleas de engaño" o la venalidad de los deportistas funcionaron como espacio de crítica de la prensa hacia las autoridades de la FAB, y también a los promotores y clubes bajo la acusación de explotar al público (El Gráfico, 10 de marzo de 1921). La Vanguardia (1 de enero de 1921:19) denunciaba a cierta prensa mercenaria que avalaba "los más sucios enjuagues de algunos 'deportistas'. Esta denuncia apuntaba a las complicidades que permitían que el deporte profesional estuviera regido por reglas poco claras, que -decían- envilecían el gusto de los trabajadores.

En muchas oportunidades era difícil determinar con exactitud si una pelea había sido arreglada, pero la disputa por el "gusto" construida a partir de la idea de la justicia en el mundo de los combates estaba sostenida por un universo simbólico que la prensa iba construyendo y transmitiendo. El Gráfico, por ejemplo, contaba que cuando Solly Young desembarcó en Buenos Aires lo hizo con un prestigio que ellos creían excesivo. Al perder con Fernando Villalba, el prestigio "excesivo" del americano pasó a "coronar" al uruguayo. Esta suerte de traspaso obligaba al boxeador a mostrarse superior “...el knock out es indispensable, jes fatal!". El boxeo exigía cierta violencia, "derribar al oponente" era la tarea. Cuando eso no se lograba, la gente solía desilusionarse. La pelea de Villalba contra Roberto Lavignase, por ejemplo, fue calificada de "tongo", porque "Villalba no puso en juego todos los recursos. Podría haber vencido por knock out" (El gráfico, 18 de Septiembre de 1920).

Los "tongos" más importantes, según relata el árbitro Benigno Rodríguez Jurado eran pelear mediante golpes blandos; desear ser descalificados mediante el uso de golpes bajos y falsos $\mathrm{KO}$, entre otros. El árbitro contaba que los tongos servían para atraer más peleas, pero a veces él tenía que amenazar al boxeador con un "levántese o no le pago" (El Gráfico, 26 de Enero de 1924). El boxeo era un trabajo y un negocio que dependía muchas veces de saber arreglar el desempeño en el ring, donde no siempre se trataba de golpes. 
Otro de los problemas era la falta de equivalencias, o la idea de que el boxeador peleaba solo con los más débiles. En ese sentido, el periodista Gastón Martínez Vázquez criticaba al boxeador Boneta; decía: "Se ha propuesto lucrar sin peligro ni sufrimiento alguno, olvidando que en la carrera del pugilista nada valen los triunfos si no están salpicados por un poquito de gloria" (El Gráfico, 23 de Julio de 1921). Estos boxeadores eran conocidos también como "usureros del ring", que suben sin "arriesgar nada" (El Gráfico, 16 de Abril de 1927).

A veces la pelea era a desgano, como la de los norteamericanos Joe Boykin y Tom Maxed, que se enfrentaron en Avellaneda, o como la de este último con Alex Rely, en la que "sobre el ring del Argentino Boxing cayeron infinidad de objetos (...) cáscaras de sandías, piedras, botellas y cuanto proyectil puede ser arrojado" (El Gráfico, 3 de Marzo de 1923), y la policía intervino con caballos para calmar a la multitud, que se había sentido engañada. De la pelea de Aurelio Borneto y Elio Plaissant se sospechó que Borneto "deseaba hacerse descalificar" lanzando golpes ilícitos, por lo cual los espectadores empezaron a pedirle al árbitro que no lo descalificara (El Gráfico, 6 de Agosto de 1921). Obligándolo a terminar la pelea.

La tragedia era de la lucha y el $\mathrm{KO}$ era en el boxeo una cuestión absolutamente necesaria. El boxeador francés Criqui comentaba que "cuando se procede solo fiando en la ciencia, en la escuela, los encuentros resultan fríos y el público se fatiga esperando la decisión (El Gráfico, 18 de Noviembre de 1922). El boxeo ocupó el lugar de la tragedia en las sociedades contemporáneas, dice Traversa (1991) -citando a Oates (2014)-, y por la magnitud de su éxito, el boxeo de alguna manera fue convirtiéndose en el teatro trágico de América, donde se hacía público el inexorable destino adverso, el fracaso y el sufrimiento del cuerpo (Morris, 1993). La tragedia que exhibía como espectáculo necesitaba presentarse ante el público como una representación verdadera de la fuerza y la destreza. Esa construcción social del espectáculo, del coraje y de la profesión de boxeador, así como también la necesidad de demandar la forma correcta de llevar a cabo un combate, tenía implícitos ciertos requisitos asociados al peligro de exponerse a riesgos. Lo que en la jerga se conocía como "corazón" y "guapeza”, y que adquiría la forma del deseo de victoria.

La necesidad de conseguir un espectáculo con tintes de verdad volvía al mundo del boxeo un área de frontera entre el deporte y el entretenimiento de las masas que comenzaba a florecer en Buenos Aires. El artificio y la falta de entrega eran castigados. En esa dirección el Púgil Club fue destruido por una multitud, luego de que una pelea se cancelara por diferencias en las onzas de guantes (Punch, 25 de Enero de 1924:6). El club L'Aglion también estuvo muchas veces al borde de ser desarmado por los espectadores.

Un poco como espectáculo, un poco como deporte, el boxeo fue un espacio social muy dinámico durante los primeros años del siglo XX y encarnó muchos sentidos que perfilaron a la sociedad de esos años. En este trabajo exploratorio quisimos plantear algunas líneas de investigación que seguirán siendo exploradas en futuras aproximaciones al problema.

\section{Organismos Oficiales E INSTITUCiOnes}

Concejo Deliberante de la Ciudad de Buenos Aires, 24 de octubre de 1922, Diario de Sesiones, p. 2162 y sig; p. 2167. Concejo Deliberante de la Ciudad de Buenos Aires, 10 de diciembre de 1923, Diario de Sesiones p. 2731; p. 2736

Cuadernos de licencias amateurs 1925-1939. Archivo de la Federación Argentina de Box.

\section{Prensa}

British Packet, and Argentine News: 24 de octubre de 1929

Caras y Caretas: 26 de octubre de 1901, p. 32. 19 de diciembre de 1908, p. 68.

Crítica, 13 de octubre de 1922. 
El Gráfico: 18 de septiembre de 1920. 15 de enero de 1921. 10 de marzo de 1921. 23 de julio de 1921. 6 de agosto de 1921.27 de mayo de 1922.8 de julio de 1922. 4 de noviembre de 1922.18 de noviembre de 1922.03 de marzo de 1923.26 de enero de 1924.26 de julio de 1924.6 de septiembre de 1924.06 de diciembre de 1924.25 de enero de 1925.16 de abril de 1927.

La Nación: 06 de septiembre de 1892. 08 de septiembre de 1892. 9 de abril de 1920: "El boxeo entre nosotros".

La Prensa: 02 y 03 de octubre de 1922

La Vanguardia: 20 de septiembre de 1910:“Box en el parque Lezama”. 1 de enero de 1921: "El año deportivo", p. 19. 7 de octubre de 1922. 9 de octubre de 1922: "El espectáculo de ayer no entusiasma al público"

Punch: 03 de noviembre de 1923, p. 13.16 de noviembre de 1923, p.6. 11 de enero de 1924: "El 1 de febrero se iniciará el campeonato de novicios del Río de la Plata" p.12. 25 de enero de 1924: "El magno espectáculo del domingo en la cueva de profesionales" p. 6.29 de marzo de 1924, p.3. 18 de abril de 1924

Revista de Policía, 1 de febrero de 1921; "Boxeo" Año XXIV, No 543, Buenos Aires, pp. 68-69.

\section{Bibliografía}

Aisenstein, A., y Feiguin, A. (2012). Identidades y valores en tensión: los inicios del hockey sobre césped en Argentina. Lúdica Pedagógica, vol. 2, No 17, pp. 9-18

Alabarces, P. (2012). Estudios sobre el deporte: por qué vale tanto la pena este libro. En J. Branz, J. Garriga Zucal y V. Moreira, (Comps.). Deporte y Ciencias Sociales: claves para pensar sociedades contemporáneas; La Plata: EDUNLP.

Allen, S. (2017). A history of boxing in Mexico. Masculinity, Modernity and Nationalism. Albuquerque: University of New Mexico Press.

Andersen, R. y Puppo, E. (2012). Historia Del Tenis en La Argentina. Buenos Aires: EP Press.

Anderson, J. (2001). Pugilistic prosecutions: prize fighting and the courts in nineteenth century Britain. The sports historian, vol. 21, pp 35-53

Archetti, E. (2001). El potrero, la pista y el ring. Las patrias del deporte argentino, Buenos Aires: FCE.

Archetti, E. (2005). El deporte en Argentina (1914-1983). Trabajo y sociedad, No 7, vol. VI, http://www.unse.edu.a r/trabajoysociedad/Archetti.pdf

Archetti, E. (2016). Masculinidades. Buenos Aires: Club House.

Archetti, E.(1995). Estilos y virtudes masculinas en El Gráfico: La creación del imaginario del fútbol argentino. Desarrollo Económico, vol. 35, no. ³9, p. 419-422.

Armus, D. (1996). La idea de verde en la ciudad moderna. Buenos Aires, 1870-1940. Entrepasados, Año V, no 10.

Arnoux Narvaja, A. (2018b). El sueño de una ciudad deportiva. El espacio libre en la ciudad de Buenos Aires en torno a la década de 1920 y su utilización para la práctica deportiva y de educación física. Tesis de Maestría, Universidad de San Martín.

Arnoux Narvaja, A. (2016). Crecimiento, diversificación y resignifiación de los Espacios Libres en la Ciudad de Buenos Aires para la práctica deportiva y de educación física: el sueño de una ciudad deportiva en las primeras décadas del siglo XX. Trabajo presentado en el IX Congreso De Historia De Avellaneda De La Provincia Y Ciudad De Buenos Aires, Avellaneda, 18 y 19 de Agosto.

Arnoux Narvaja, A. (2018a). El fenómeno deportivo y la forma de encarar su análisis histórico: el caso del boxeo en la ciudad de Buenos Aires a principios del siglo XX. Jornadas del Centro de Estudios de Historia e Historia del Arte.

Barrancos, D. (2014). Prólogo. En P. Scharagrodsky (comp.), Miradas médicas sobre la cultura fisica en Argentina, 1880-1970. Buenos Aires: Prometeo.

Bergel, M. y Palomino, P. (2000). La revista El Gráfico en sus inicios: una pedagogía deportiva para la ciudad moderna. Prismas, No4, pp. 103-122.

Bolio, E. (1923). El box en las escuelas públicas. Su importancia educativa. Diario Oficial del Gobierno del Estado de Yucatán, 6 de noviembre 
María Ullivarri. BoXeo, espectáculo y deporte. Hacia la construcción de una institucionalidad PUGi...

Bontempo, P. (2012).Editorial Atlántida. Un continente depublicaciones, 1918-1936. Tesis de doctorado, Universidad de San Andrés.

Buonuome, J. (2016). Periodismo militante en la era de la información. La Vanguardia, el socialismo y los origenes de la cultura de masas en la Argentina (1894-1930). Tesis de Doctorado, Universidad de San Andrés.

Carelli Lynch, G. y Bordón, J.M. (2017). Luna Park. El estadio del pueblo, el ring delpoder. Buenos Aires: Sudamericana.

Cecchi, A. (2012). La timba como rito de pasaje: la narrativa del juego en la construcción de la modernidad porteña (1900-1935). Buenos Aires: Teseo

Cortés Ancona, J. (2015). El campo del boxeo en ;Esta noche, gran velada! ¡Kid Peña contra Alarcón por el título europeo!, de Fermin Cabal, y iPelearán diez rounds!, de Vicente Leñero. Estudio comparativo. Tesis de Doctorado. Sevilla: Universidad de Sevilla.

Demarcico, J. (1997). Historia del boxeo aficionado en la Argentina, Tomo 1, Buenos Aires: Ed. Del autor.

Elias, N. y Dunning, E. (2016). El deporte y el ocio en el proceso de la civilización, Buenos Aires: FCE.

Estol, H. (1946). Vida y combates de Luis Angel Firpo. Buenos Aires: Bell.

Elsey, B. (2011). Citizen and sportsmen. Football and Politics in TwentiethCentury Chile. Austin: University of Texas Press.

Frydenberg, J. (2011). Historia Social del Fútbol. Del amateurismo a la profesionalización. Buenos Aires: Siglo XXI.

González Velazco, C. (2012). Gente de teatro. Ocio y espectáculos en la Buenos Aires de los años veinte. Buenos Aires: Siglo XXI.

Guiamet, J. (2016). El trompeador Firpo. El boxeo dentro del imaginario del socialismo argentino de los años veinte. Anuario de la Escuela de Historia Virtual, Año 7, № 9, pp. 61-80.

Gumbrecht, H. (2006). Elogio de la belleza atlética. Buenos Aires: Katz.

Hora, R. (2014). Historia del turf argentino. Buenos Aires: Siglo XXI.

Iwanzuk, J. (1992). Historia del fútbol amateur en la Argentina. Buenos Aires: Ed. Del autor.

Karush, M. (2013). Cultura de clase. Radio y cine en la creación de una Argentina dividida (1920-1946). Buenos Aires: Ariel.

Losada, L. (2009). Historia de las elites en la Argentina. Desde la conquista hasta el surgimiento del peronismo. Buenos Aires: Sudamericana.

Loudcher, J. y Day, D. (2013). The International Boxing Union (1913-1946): A European Sports and/or Political Failure?. The International Journal of the History of Sport, Vol. 30, No 17.

Martínez Mazzola, R. (2013). Gimnasia, deportes y usos del tiempo libre en el socialismo argentino (1896-1916). En P. Scharagrodsky (comp.) Miradas médicas sobre la "cultura fisica" en Argentina (1880-1970). Buenos Aires: Prometeo.

Moreira, V. (2016). Mujer y antropóloga en un gimnasio de box. La Plata: Jornadas de Sociología de la Universidad Nacional de La Plata.

Morris, D. (1993). La cultura del dolor. Santiago de Chile: Andrés Bello.

Mosse, G. (1985). Nationalism and sexuality, Middle class morality and sexual norms in modern Europe. Wisconsin: The University of Wisconsin Press.

Oates, C. (2014). Del Boxeo. Buenos Aires: Punto de Lectura

Otero Carvajal, L. (2003). Ocio y deporte en el nacimiento de la sociedad de masas. Cuadernos de Historia Contemporánea 25. pp. 169-198.

Palla, J. (2016). La Industria Cultural en Buenos Aires durante la primera mitad del siglo XX : El caso del Stadium Luna Park. Tesis de Licenciatura en Historia, Facultad de Filosofía y Letras, Universidad de Buenos Aires.

Palla, J. (2018). Bitácora de Willie Farrell. Pugilismo, escenarios y negocios a ambos lados del Atlántico. (1920-1960). Revista Claves, Vol. 4, No 7, pp. 57-86.

Rauch A. (1993). Violence et maîtrise de soi en boxe. Communications, 56, Le gouvernement du corps, sous la direction de Georges Vigarello. pp. 139-154 
Reyna, F. (2011). Cuando éramosfootballers. Una historia sociocultural del surgimiento y la difusión del fútbol en Córdoba (1900 - 1920). Córdoba: Centro de Estudios Históricos "Prof. Carlos S.A. Segreti".

Reyna, F. (2015). La emergencia del profesionalismo en el fútbol de Córdoba (Argentina). Recorde, V. 8, n.1. pp.1-23

Rinke, S. (2007). ¿La última pasión verdadera? Historia del fútbol en América Latina en el contexto global. Iberoamericana, VII, 27, pp. 85-100;

Rodríguez, R. (2009). The regulation of boxing. A history and comparative analysis of policies among American states. North Carolina: McFarland.

Roldán, D. (2009). ¿Qué hacer con el tiempo? Intentos reguladores y estrategias de resistencia sobre los usos del tiempo libre: un campo conflictivo. Los sectores populares de Rosario 1910-1945. Tesis de Doctorado, Universidad Nacional de Rosario.

Roldán, D. (2015). Circulación, difusión y masificación. El fútbol en Rosario (Argentina) 1900-1940. Secuencia, No 93, pp.137-161

Romero Brest, E. (1929). El Box. Buenos Aires: La Vanguardia/Sociedad Luz.

Runstedtler, T. (2012). Jack Johnson, Rebel Sojourner. Boxing in the Shadow of the Global Color Line. University of California Press.

Scharagrodsky, P. (Comp) (2011). La invención del homo-gymnasticus, Fragmentos históricos sobre la educación de los cuerpos en movimiento en Occidente. Buenos Aires: Prometeo.

Scharagrodsky, P. (Comp) (2014). Miradas médicas sobre la cultura fisica en Argentina, 1880-1970, Buenos Aires: Prometeo.

Scott, D. (ed.) (2015). Cultures of boxing. Berna: Peter Lang.

Servera, L. (2017). De amateurs a profesionales. La profesionalización del fútbol en Argentina (1925-1931). Tesis de Licenciatura, Universidad Torcuato Di Tella.

Taylor, M. (2009). Round the London Ring: boxing, class and community in Interwar London. The London Journal, Vol. 34, No 2, pp.139-162.

Taylor, M. (2013). The global ring? Boxing, mobility, and transnational networks in the Anglophone world, 1890-1914. Journal of Global History, Vol. 8, Issue 2.

Traversa, O. (1991). Figuraciones del cuerpo en la prensa. 1918-1940. Tesis de Doctorado. Universidad de Buenos Aires.

Ulanovsky, C. et al (2009). Dias de radio, 1920-1959. Buenos Aires: EMECE.

Viale, C. (1922). El Deporte argentino. Buenos Aires: Librería de A. García de los Santos.

Vila, J. (2011). El boxeo y yo. Anecdotario pugilístico, 1829-2009. Buenos Aires: El Arco.

Wacquant, L. (2007). Carisma y Masculinidad y el boxeo. Debate Feminista, Vol, 36, Octubre, pp. 30-40

Wacquant, L. (2011). El punto de vista del boxeador: cómo piensan y sienten los boxeadores sobre su profesión. Educación física y ciencia, año 13, Depto de Educación Física, UNLP.

\section{Notas}

1 A pesar de que Firpo lograba convocar multitudes impensadas hasta entonces, los estudios académicos sobre la historia del pugilismo son escasos (Archetti, 2001; Palla, 2018, 2016; Arnoux Narvaja, 2018; Guiamet, 2016, Moreira, 2016). Desde la sociología las investigaciones de Pablo Alabarces (2012) dieron forma a un núcleo de estudios sociales del deporte articulando redes y nuevas discusiones. Sin embargo, el boxeo recién comenzó a ser analizado por Verónica Moreira (2016) a partir de una etnografía sobre su práctica.

2 El 17 de julio de 1892 el diario La Nación hizo referencia a una pelea en el salón La France entre los británicos Tom Bull y George Davies. Dos meses después, el mismo diario informó sobre un permiso otorgado para otro match en un teatro.

3 "Boxeo" en Revista de Policía, 1 de febrero de 1921; Año XXIV, No 543, Buenos Aires, pp. 68-69. Quiero agradecer a Diego Galeano por facilitarme esta crónica. 
4 Parte de esa arqueología puede verse en los nombres de los primeros clubes deportivos, todos ellos escritos en inglés. River Plate Rowing Club, Buenos Aires Rowing Club, Buenos Aires Lawn Tennis Club, Jockey Club, Athletic Club Lomas, Boxing Club de Buenos Aires.

5 Las reglas del marqués de Queensberry datan de 1860 y pretendían garantizar una práctica equivalente y eficiente, para dotar al boxeo un tinte moderno que permitiera argumentar que su práctica nada tenía que ver con la riña. En este sentido se reglamentó el uso de guantes, la cantidad de rounds y el tiempo de combate y de descanso, se prohibieron los agarres y se establecieron categorías de peso.

6 La elección de esa pelea como la primera quizás responda a la visibilidad del enfrentamiento que contó con autoridades del ring destacadas y la presencia de muchas personalidades de la política y la sociedad porteña. Fue además documentada y reglamentada de acuerdo a las normas internacionales. Incluso, y a pesar de que el boxeo estaba prohibido, el jefe de policía ofició de time-keeper.

7 La mayoría de ellos con protagonistas extranjeros que vivían en el país como los combatientes de El Gladiador. O como el irlandés Willie Gould que peleó por el título argentino en 1908 y el sudamericano en 1910. Luego otro hito destacado fue la pelea de Jack Johnson contra Jack Murray en 1915. Además del campeón negro Johnson, también visitaron Buenos Aires grandes boxeadores afroamericanos como Sam Langdford y Sam MacVea. Buenos Aires era considerada una plaza donde los boxeadores afroamericanos se sentían cómodos. Runstedler (2012, p. 572) señala que llegaron 18 mil "bien educados, arreglados y equipados hombres y mujeres de color desde los Estados Unidos de América”, muchos de ellos, boxeadores.

8 De esa reunión en fundacional en la calle Corrientes 327, sede del Club Universitario, salió la Comisión Directiva y el primer Reglamento de Box para aficionados. Estaban presentes representantes del Jockey Club, Club del Progreso, Club Universitario, Saavedra Boxing Club, GEBA, Boxing Club de Buenos Aires, Hue Gen Club, Club Policial de Cultura Física, Círculo Militar, Centro Naval, Círculo de la Prensa, Urquiza Boxing Club, Flores Boxing Club, Círculo de Belgrano, Nacional Sport Club y el Club Sportivo Barracas.

9 Este pedido intentaba emular las reglamentaciones de algunos estados de Estados Unidos donde se permitía el boxeo, pero no el KO, convirtiendo las peleas en exhibiciones. En ese sentido, cuando Firpo se presentó en Indianápolis, contra Joe Downey la prensa relataba que en caso de noquear a su adversario, podría ir preso.

10 Las medallas fueron las de Alfredo Copello, Horacio Lavalle y Manuel Gallardo.

11 En la pelea de Borneto contra Arregui, por ejemplo, donde había 12 kilos de diferencia, se prohibió el infighting o pelea de rango corto o "por dentro", permitiéndose a los boxeadores solo pelear a la distancia. El Gráfico, 23 de septiembre de 1922. O la de Plaisant con Walter, donde con 10 kilos de diferencia, uno uso guantes de 6 onzas y el otro de 4 . El Gráfico, 7 de octubre de 1922.

12 El punto más álgido ocurrió en la pelea de Galtieri contra Plaissant, que implicaba el debut fiscalizador de la AAB. La noche del combate, miembros de la FAB se llevaron a Plaissant a comer y a beber. El boxeador llegó borracho y tarde a la pelea y tuvieron que sacarlo en un camión de policía para resguardarlo de la ira popular.

13 Luego de la unión de la $\mathrm{AAB}$ y la $\mathrm{FAB}$, la misma FAB se dividió en dos Federaciones, una reconocida por el estado nacional y otra por la ciudad de Buenos Aires. Los conflictos estaban vinculados a las internas de los clubes. La puja se daba entre los clubes más tradicionales como GEBA y el Boxing Club, que tenían vínculos con el Comité Olímpico, creado por decreto del presidente Alvear y el resto de los clubes que reconocían a la Confederación Argentina de Deportes, compuesta en 1921 por las distintas federaciones deportivas, como el organismo a cargo de designar las comitiva que participaría de los Juegos Olímpicos de Paris. De todas formas el boxeo participó y ganó 2 medallas de plata y una de bronce.

14 Las licencias tenían un costo: $\$ 1000$ para promotores y para locales, $\$ 100$ para representantes, $\$ 50$ para pugilistas, referís y jueces profesionales y $\$ 25$ para segundos y masajistas. Versión taquigráfica, Diario de Sesiones Concejo Deliberante de la Ciudad de Buenos Aires, 28 de diciembre de 1923, p. 3246 y Actas de la Comisión Municipal de Box, Tomo 1. 6 de febrero de 1924. Archivo CeDirH.

15 Frydemberg (2011) señala algo similar para el caso del fútbol, destacando que este deporte ayudó fuertemente a conformar una identidad vecinal y barrial porteña.

16 Este juego consistía en vendar los ojos de un gran número de boxeadores y subirlos al ring para que se peguen a ciegas.

17 El monto de las bolsas se desprende del análisis de: Licencias de boxeadores profesionales, libros 1, 2 y 3. Comisión Municipal de Box. Archivo CeDHirH.

\section{BY-NC-SA}

